\title{
Composição Química e Valores de Energia Metabolizável das Farinhas de Penas e Vísceras Determinados por Diferentes Metodologias para Aves ${ }^{1}$
}

\author{
Adriana Helena do Nascimento ${ }^{2}$, Paulo Cezar Gomes ${ }^{3}$, Luiz Fernando Teixeira Albino ${ }^{3}$, \\ Horacio Santiago Rostagno ${ }^{3}$, Robledo de Almeida Torres ${ }^{3}$
}

\begin{abstract}
RESUMO - Uma série de experimentos foi realizada com o objetivo de estabelecer o valor nutritivo de nove farinhas de vísceras e de seis farinhas de penas para aves. Quatro diferentes metodologias foram utilizadas para determinar os valores de energia metabolizável aparente corrigida (EMAn) e verdadeira corrigida (EMVn): método tradicional (com pintos e galos) e método de Sibbald (com galos inteiros e galos cecectomizados). Os valores de EMAn e EMVn da farinha de vísceras estimados variaram de 3.051 a 3.621 e de 2.866 a $3.583 \mathrm{kcal} / \mathrm{kg}$, respectivamente. Para a farinha de penas os valores variaram de 2.952 a 3.629 e de 2.703 a $3.671 \mathrm{kcal} / \mathrm{kg}$ para a EMAn e EMVn, respectivamente. Entre as metodologias realizadas para determinação dos valores energéticos dos alimentos, as correlações foram baixas, portanto, as diferenças nos valores energéticos dos alimentos podem ser atribuídas à metodologia empregada.
\end{abstract}

Palavras-chave: aves, energia metabolizável, farinha de vísceras, farinha de penas, metodologia

\section{Chemical Composition and Metabolizable Energy Values of Feathers Meal and Poultry By-Product Meal Determined by Different Methodologies for Chickens}

\begin{abstract}
A serie of experiments was carried out with the objective to determine the nutritive value of nine poultry by-product meal and six feather meal for chickens. Four different methodologies were used to determine the values of N corrected apparent (AMEn) and true corrected (TMEn) metabolizable energy, where the traditional method was used with chicks and cocks and the Sibbald method was used with roosters and cecectomized cocks. The estimated AMEn and TMEn values of viscera meal ranged from 3,051 to 3,621 and from 2,866 to $3,583 \mathrm{kcal} / \mathrm{kg}$, respectively. Feathers meal values ranged from 2,952 to 3,629 and from 2,703 to 3,671 kcal/kg for AMEn and TMEn, recpectively. Among the methodologies to determine the feeds energy, the correlations were low, so the differences on the feeds energy values were due to the methodology used.
\end{abstract}

Key Words: feather meal, metabolizable energy, methodologies, poultry, viscera meal

\section{Introdução}

Os nutricionistas têm a preocupação de formular rações para que as aves obtenham máximo desempenho de forma econômica. O conhecimento da composição química e energética dos alimentos é de suma importância para a formulação de rações, principalmente para os produtos de origem animal, que apresentam valores variados, devido ao processamento a que são submetidas, ao tipo e à proporção dos constituintes das farinhas. Segundo Albino e Silva (1996), isso ocorre pela dificuldade das seções de graxarias de abatedouros em adotar um padrão contínuo no material produzido.

Atualmente, a utilização dos subprodutos do abate das aves tais como as farinhas de vísceras, penas e mista (vísceras + penas) nas rações, é uma realidade, mas a definição do seu conteúdo energético torna-se necessário para maximizar o desempenho e o retorno econômico da atividade.

A descrição da energia útil de um alimento para as aves é muito complexa, pois todos os componentes orgânicos do alimento, sujeitos à digestão e absorção pelas aves, contribuem com energia, mesmo tendo diferentes destinos no organismo animal. Além disso, a energia não é um nutriente, e sim o resultado da oxidação dos nutrientes durante o metabolismo.

A energia é um dos fatores nutricionais importantes na formulação de ração, pois interfere diretamente no desempenho das aves, sendo considerada também um dos elementos mais caros das rações de frangos de corte. Assim, para maior precisão na formulação de rações, torna-se necessário estimar o correto valor de energia metabolizável dos alimentos.

\footnotetext{
${ }^{1}$ Parte da tese de Doutorado em Nutrição de Monogástricos do primeiro autor apresentada à UFV.

2 Zootecnista - Ajinomoto Biolatina. E.mail: adriana_nascimento@bil.ajinomoto.com

3 Professores do Departamento de Zootecnia da Universidade Federal de Viçosa.
} 
Existem várias metodologias para determinar o valor de energia metabolizável do alimento e inúmeras terminologias para expressar esse valor. Todas possuem alguns equívocos e pouco evoluíram durante os últimos anos, mas ainda são consideradas importantes ferramentas para determinar a quantidade de energia disponível do alimento para as aves.

A determinação da composição química e dos valores de energia metabolizável das farinhas de vísceras e penas, bem como a comparação desses valores determinados por diferentes metodologias, foi o objetivo deste trabalho.

\section{Material e Métodos}

Os ensaios biológicos foram realizados no Setor de Avicultura do Departamento de Zootecnia da Universidade Federal de Viçosa, com a finalidade de determinar os valores de energia metabolizável de nove farinhas de vísceras e seis farinhas de penas de diferentes procedências e obtidos por várias metodologias.

\section{Ensaio 1 - Metodologia tradicional com pintos}

Utilizou-se o método de coleta total de excretas, com pintos de corte de 16 a 23 dias de idade. O período experimental foi de oito dias, sendo três dias para adaptação das aves às rações experimentais e às baterias e cinco dias para a coleta das excretas. Foram utilizados 640 pintos de corte machos da marca comercial Avian Farms, distribuídos em delineamento inteiramente ao acaso, para nove farinhas de vísceras (aves e suínos) e seis para farinhas de penas, com quatro repetições e 10 aves por unidade experimental. As médias de temperatura máxima e mínima, durante o período experimental, foram $26 \mathrm{e}$ $15^{\circ} \mathrm{C}$, respectivamente.

As farinhas de vísceras, bem como as farinhas de penas, substituíram 30\% uma ração-referência (Tabela 1), de forma que a ração teste fosse composta de $70 \%$ da ração-referência e $30 \%$ da farinha de vísceras ou de penas.

Paralelamente, foram mantidas quatro repetições de 10 aves em jejum, por 84 horas, sendo as primeiras 36 horas para a limpeza do trato gastrintestinal e às 48 horas subseqüentes para a coleta das excretas, com a finalidade de determinar as perdas energéticas endógenas e metabólicas.

Os pintos foram alojados em baterias metálicas aos 16 dias de idade, com peso médio de $325 \mathrm{~g}$, e
Tabela 1 - Composição percentual da ração-referência Table 1 - Composition percentage of the reference-ration

\begin{tabular}{|c|c|}
\hline $\begin{array}{l}\text { Ingredientes } \\
\text { Ingredients }\end{array}$ & $(\%)$ \\
\hline Milho & 56,040 \\
\hline \multicolumn{2}{|l|}{ Corn } \\
\hline Farelo de soja & 37,060 \\
\hline \multicolumn{2}{|l|}{ Soybean meal } \\
\hline Óleo de soja & 2,800 \\
\hline \multicolumn{2}{|l|}{ Soybean oil } \\
\hline Calcário & 0,880 \\
\hline \multicolumn{2}{|l|}{ Limestone } \\
\hline Fosfato bicálcico & 2,310 \\
\hline \multicolumn{2}{|l|}{ Dicalcium phosphate } \\
\hline Mistura mineral* & 0,050 \\
\hline \multicolumn{2}{|l|}{ Mineral mix* } \\
\hline Mistura vitamínica** & 0,100 \\
\hline \multicolumn{2}{|l|}{ Vitamin mix $* *$} \\
\hline Sal & 0,320 \\
\hline \multicolumn{2}{|l|}{ Salt } \\
\hline BHT (antioxidante) & 0,010 \\
\hline \multicolumn{2}{|l|}{ Antioxidant } \\
\hline Bacitracina de zinco & 0,010 \\
\hline \multicolumn{2}{|l|}{ Bacitracin zinc } \\
\hline Cloreto de colina $(60 \%)$ & 0,060 \\
\hline \multicolumn{2}{|l|}{ Choline chloride } \\
\hline Anticoccidiano & 0,100 \\
\hline \multicolumn{2}{|l|}{ Anticoccidian } \\
\hline DL-metionina (99\%) & 0,260 \\
\hline \multicolumn{2}{|l|}{ DL-methionine } \\
\hline Total $(\%)$ & 100,000 \\
\hline \multicolumn{2}{|c|}{ Composição calculada } \\
\hline Proteína bruta (\%) & 21,50 \\
\hline \multicolumn{2}{|l|}{ Crude protein } \\
\hline Energia metabolizável (kcal/kg) & 3.020 \\
\hline \multicolumn{2}{|l|}{ Metabolizable energy } \\
\hline Cálcio (\%) & 0,990 \\
\hline \multicolumn{2}{|l|}{ Calcium } \\
\hline Fósforo disponível (\%) & 0,510 \\
\hline \multicolumn{2}{|l|}{ Available P } \\
\hline Lisina $(\%)$ & 1,192 \\
\hline \multicolumn{2}{|l|}{ Lysine } \\
\hline Metionina (\%) & 0,590 \\
\hline \multicolumn{2}{|l|}{ Methionine } \\
\hline Metionina + Cistina (\%) & 0,946 \\
\hline \multicolumn{2}{|l|}{ Meth + Cys } \\
\hline Sódio (\%) & 0,170 \\
\hline Sodium & \\
\hline
\end{tabular}

* Mistura mineral (Mineral mix) (kg do produto) - Fe - $80 \mathrm{~g}$; Cu- 10 g; Co - 2 g; Mn - 80 g; Zn - 50 g; I - 1 g; e Excipiente q.s.p., $500 \mathrm{~g}$.

** Mistura vitamínica (Vitamin mix) (kg do produto) - Vit. A, 15.000.000 UI; Vit. $D_{3}, 1.500 .000$ UI; Vit. E, $15.000 U I$ Vit. $B_{1}, 2,0$ g; Vit. $B_{2}$, 4,0 g; Vit. $B_{6}, 3,0$ g; Vit. B $12,0,015$ g; Ácido nicotínico - (Nicotinic acid), $25 \mathrm{~g}$; Ácido pantotênico - (Pantothenic acid), $10 \mathrm{~g}$, Vit. $\mathrm{k}_{3}$, 3,0 g; Ácido fólico- (Folic acid) 1,0 g; Colina - (Choline), 250 g; Selênio (seleniun), $100 \mathrm{mg}$; Antioxidante (antioxidant)., $10 \mathrm{~g}$; e excipiente q.s.p., $1.000 \mathrm{~g}$. 
tiveram o fornecimento de rações testes e água à vontade. A coleta das excretas, foram recolhidas em bandejas forradas com plástico e colocadas sob as gaiolas para evitar perda do material, iniciou-se logo após o período de adaptação. O intervalo das coletas foi de 12 horas, durante todo o período experimental, para evitar a fermentação das excretas.

As excretas foram acondicionadas em sacos plásticos, identificadas por repetição e, após cada coleta, pesadas e armazenadas em congelador. Ao término do período experimental, foram determinados o consumo de ração e a quantidade total de excretas.

As amostras das excretas foram reunidas por repetições e homogeneizadas, e uma amostra de cada repetição foi retirada e colocada em estufa de ventilação forçada, à temperatura de $55^{\circ} \mathrm{C}$, para efetuar a pré-secagem. As amostras dos alimentos e das excretas foram encaminhadas ao Laboratório de Nutrição Animal do Departamento de Zootecnia da Universidade Federal de Viçosa, para efetuar as análises de matéria seca, nitrogênio e energia bruta, segundo as metodologias descritas por Silva (1990).

Com base nos resultados das análises, calcularamse os valores de energia metabolizável aparente corrigida para nitrogênio (EMAn), usando as equações proposta por Matterson et al. (1965). Também foram determinados os valores de energia metabolizável verdadeira corrigida para nitrogênio (EMVn).

\section{Ensaio 2 - Metodologia tradicional com galos}

Neste ensaio, também foi utilizado o método tradicional de coleta total de excretas, porém com galos adultos da linhagem Leghorn. O período experimental foi de oito dias, sendo os três primeiros dias para a adaptação dos galos às rações testes, bem como às gaiolas, e cinco dias para a coleta das excretas. As médias de temperatura máxima e mínima, durante o período, foram de 25 e $18^{\circ} \mathrm{C}$, respectivamente. $\mathrm{O}$ ensaio foi realizado em baterias metálicas composta por gaiolas, nas quais foram alojados dois galos por gaiola, com peso médio de $2.110 \mathrm{~g}$. O delineamento experimental foi o inteiramente ao acaso, para as nove farinhas de vísceras (aves e suínos) e as seis farinhas de penas, em quatro repetições e duas aves por unidade experimental.

Paralelamente, quatro repetições de dois galos por repetição foram mantidas em jejum por um período de 84 horas, sendo as primeiras 36 horas destinadas à limpeza do trato gastrintestinal e às 48 horas

R. Bras. Zootec., v.31, n.3, p.1409-1417, 2002 (suplemento) subseqüentes à coleta das excretas, para determinar as perdas energéticas endógenas e metabólicas.

Foram fornecidas às aves ração e água à vontade, sendo as rações testes e a ração-referência as mesmas do experimento 1 .

O procedimento da coleta das excretas, a amostragem e secagem das excretas, a rotina durante e após o período experimental e as equações utilizadas para a determinação dos valores de energia metabolizável das farinhas de vísceras e penas foram semelhantes ao ensaio 1.

Ensaio 3 - Metodologia da alimentação forçada com galos (Método de Sibbald)

A metodologia utilizada neste ensaio foi a da alimentação forçada descrita por Sibbald (1976), com galos adultos da linhagem Leghorn. O experimento foi realizado em baterias metálicas, onde 90 galos com peso médio de 1.950 gramas foram distribuídos em um delineamento inteiramente ao acaso, em nove farinhas de vísceras e seis farinhas de penas, com seis repetições e uma ave por unidade experimental. Os galos foram submetidos a um período de adaptação às gaiolas e às rações experimentais de cinco dias e receberam ração e água à vontade. As médias da temperatura máxima e mínima, durante o período experimental, foram de $24 \mathrm{e}$ $16^{\circ} \mathrm{C}$, respectivamente.

Após o período de adaptação, as aves foram submetidas ao período experimental de 92 horas, sendo que nas primeiras 36 horas permaneceram em jejum para o esvaziamento do trato gastrintestinal. Após o período de jejum, foram forçados a ingerir 30 gramas do alimento teste, fornecidos em duas partes, às 8 e $16 \mathrm{~h}$, para evitar que os galos regurgitassem o alimento fornecido. $\mathrm{O}$ fornecimento do alimento foi feito, por meio de um funil, via esôfago até o papo.

Concomitantemente, seis repetições de um galo por unidade experimental foram mantidas em jejum, para a determinação das perdas metabólicas energéticas e endógenas.

A coleta de excretas foram realizadas por um período de 56 horas após o primeiro fornecimento do alimento teste, em intervalos de 12 horas, para evitar a fermentação da excretas, que foram recolhidas em bandejas revestidas por plásticos, alojadas sob as gaiolas. As excretas foram acondicionadas em sacos plásticos e congeladas.

Ao término do ensaio, as amostras foram homogeneizadas e levadas para estufa de ventilação forçada, a $55^{\circ} \mathrm{C}$, para posteriores análises de 
matéria seca, nitrogênio e energia bruta, juntamente com as amostras dos alimentos, semelhante ao ensaio 1.

As equações para determinação dos valores de energia metabolizável das farinhas de vísceras e penas foram idênticas às do ensaio 1 .

Ensaio 4 - Metodologia da alimentação forçada com galos cecectomizados (Método de Sibbald)

A metodologia utilizada neste ensaio foi a da alimentação forçada descrita por Sibbald (1976), com galos adultos cecectomizados pesando em média 2.130 gramas, da linhagem Leghorn. As médias de temperatura máxima e mínima, durante o período experimental, foram de 25 e $20^{\circ} \mathrm{C}$, respectivamente.

A cecectomia dos galos foi realizada, segundo a metodologia descrita por Pupa et al. (1998), no Setor de Avicultura do Departamento de Zootecnia da Universidade Federal de Viçosa.

O delineamento experimental, bem como os procedimentos para realizar essa metodologia, foram os mesmos do ensaio 3.

Análises estatísticas

As análises estatísticas foram processadas utilizando-se o Sistema de Análises Estatísticas - SAEG (Universidade Federal de Viçosa - UFV (1992). Os valores de energia metabolizável foram analisados em um delineamento inteiramente casualizado, e as médias foram comparadas pelo teste de Newman Keuls a 5\% de probabilidade. O modelo estatístico utilizado para análise de variância foi:

$$
\mathrm{Y}_{\mathrm{ijk}}=\mathrm{m}+\mathrm{Al}_{\mathrm{i}}+\mathrm{Me}_{\mathrm{j}} / \mathrm{Al}_{\mathrm{i}}+\mathrm{e}_{\mathrm{ijk}}
$$

em que: $Y_{i j k}=$ observação da unidade experimental; $\mathrm{m}=$ média geral; $\mathrm{Al}_{\mathrm{i}}=$ efeito dos alimentos; $\mathrm{Me}_{\mathrm{j}} / \mathrm{Al}_{\mathrm{i}}=$ efeito dos métodos $\mathrm{j}(\mathrm{j}=1,2,3 \mathrm{e} 4)$ para cada alimento; e $\mathrm{e}_{\mathrm{ijk}}=$ erro aleatório associado a cada observação.

\section{Resultados e Discussão}

\section{Composição química e energética}

A composição química, energética e física dos alimentos estudados está apresentada na Tabela 2 .

As farinhas de vísceras de suínos foram as que apresentaram menor teor de proteína bruta. Foi encontrada diferença de $16,63 \%$ no conteúdo de proteína bruta das farinhas de vísceras de aves e suínos, entretanto, nos resultados da Empresa Brasileira de Pesquisa Agropecuária - EMBRAPA (1991), verificou-se que a diferença é de apenas $1,77 \%$. Obtevese conteúdo máximo de $67,44 \%$ e mínimo de $45,34 \%$ de proteína bruta, com uma diferença entre as farinhas de vísceras de $22,10 \%$. Em relação às farinhas de penas, encontrou-se valor máximo de $81,87 \%$ e mínimo de $72,29 \%$ de proteína bruta, apresentando diferença de $9,58 \%$, bem menor quando comparado com as farinhas de vísceras.

As farinhas de vísceras de suínos apresentaram maior conteúdo de extrato etéreo, sendo obtida média de 13,55 e $4,42 \%$ para as farinhas de vísceras e penas, respectivamente. Resultados semelhantes podem ser observados no NRC (1998). Entretanto, foi observado que o conteúdo de extrato etéreo das farinhas de penas foi mais variável que o das farinhas de vísceras. Observou-se também, variação na energia bruta dos alimentos; os valores médios encontrados discrepam dos observados por Albino et al. (1992), sendo que as farinhas de vísceras apresentaram variação de $1.782 \mathrm{kcal} / \mathrm{kg}$ e as farinhas de penas, de $247 \mathrm{kcal} / \mathrm{kg}$. As farinhas de vísceras aves $1 \mathrm{e} \mathrm{mista}$ 2 obtiveram maiores valores de energia bruta (EB), provavelmente em razão de apresentarem baixos teores de matéria mineral (MM). Resultados semelhantes foram encontrados por Azevedo (1997) com a farinha de carne e ossos.

As farinhas de vísceras mistas 1 e 2 foram as que apresentaram o maior e menor teor de fibra bruta, respectivamente, entre as farinhas de vísceras. A farinha de vísceras suínos 1 apresentou alto conteúdo de matéria mineral $(\mathrm{MM})$, cálcio $(\mathrm{Ca})$ e fósforo $(\mathrm{P})$, o que provavelmente contribuiu para o seu baixo conteúdo de energia bruta (EB), pois essa farinha continha elevado teor de extrato etéreo. A farinha de penas 4 também destacou-se por sua pequena quantidade de $\mathrm{Ca}$ e a farinha de penas 1 , pelo elevado teor de $\mathrm{Ca}$ e $\mathrm{P}$.

Zanotto \& Bellaver (1996) consideram a classificação das partículas dos Tabela 2 - Composições química, energética e física das farinhas de vísceras e penas alimentos em finas (DGM $<0,60 \mathrm{~mm}$ ), médias (DGM 0,60 a 2,00 mm) e grossas (DGM > $2,00 \mathrm{~mm}$ ). Segundo esta classificação, apenas as farinhas de vísceras aves 1 e 2 são consideradas de granulometria fina; as demais farinhas de vísceras, bem como as farinhas de penas, são de granulometria média. Sarvory (1979), citado por Rutz et al. (1999), sugeriu que o tamanho e a consistência das partículas do alimento afetam as respostas sensoriais que promovem alteração no consumo.

De acordo com o padrão ANFAR (1998), para as farinhas de vísceras, o mínimo de PB é de $58 \%$, no entanto, somente as farinhas de vísceras aves 5 e a 
Tabela 2 - Composições química, energética e física das farinhas de vísceras e penas Table 2 - Chemical, energy and physical composition in the viscera and feathers meal

\begin{tabular}{|c|c|c|c|c|c|c|c|c|c|}
\hline $\begin{array}{l}\text { Alimento } \\
\text { Feedstuff }\end{array}$ & $\begin{array}{l}\text { MS } \\
(\%)\end{array}$ & $\begin{array}{l}\text { PB } \\
(\%)\end{array}$ & $\begin{array}{l}\mathrm{EE} \\
(\%)\end{array}$ & $\begin{array}{c}\mathrm{EB} \\
(\mathrm{kcal} / \mathrm{kg})\end{array}$ & $\begin{array}{l}\text { FB } \\
(\%)\end{array}$ & $\begin{array}{c}\mathrm{MM} \\
(\%)\end{array}$ & $\begin{array}{c}\mathrm{Ca} \\
(\%)\end{array}$ & $\begin{array}{l}\mathrm{P} \\
(\%)\end{array}$ & $\begin{array}{r}\mathrm{DGM}^{*} \\
(\mathrm{~mm})\end{array}$ \\
\hline $\begin{array}{l}\text { F. vísceras aves } 1 \\
\text { Viscera meal } 1\end{array}$ & 95,17 & 57,70 & 13,68 & 5.566 & 1,18 & 15,67 & 3,23 & 2,11 & 0,523 \\
\hline $\begin{array}{l}\text { F. vísceras aves } 2 \\
\text { Viscera meal } 2\end{array}$ & 90,19 & 56,34 & 12,16 & 4.683 & 1,15 & 12,74 & 3,16 & 3,44 & 0,440 \\
\hline $\begin{array}{l}\text { F. vísceras aves } 3 \\
\text { Viscera meal } 3\end{array}$ & 92,71 & $47,4 b^{3}$ & 10,14 & 3.784 & 1,56 & 24,93 & 3,34 & 2,87 & 0,585 \\
\hline $\begin{array}{l}\text { F. vísceras aves } 4 \\
\text { Viscera meal } 4\end{array}$ & 91,96 & 48,53 & 13,69 & 4.169 & 1,57 & 21,63 & 2,89 & 2,08 & 0,631 \\
\hline $\begin{array}{l}\text { F. vísceras aves } 5 \\
\text { Viscera meal } 5\end{array}$ & 93,15 & 58,18 & 14,21 & 4.884 & 1,28 & 12,59 & 3,53 & 3,61 & 0,724 \\
\hline $\begin{array}{l}\text { F. vísceras mista } 1 \\
\text { Mix viscera meal } 1\end{array}$ & 93,57 & 53,77 & 11,30 & 4.677 & 2,28 & 18,24 & 6,37 & 4,00 & 0,680 \\
\hline $\begin{array}{l}\text { F. vísceras mista } 2 \\
\text { Mix viscera meal } 2\end{array}$ & 89,75 & 67,44 & 15,63 & 5.173 & 0,50 & 12,67 & 2,50 & 1,79 & 1,245 \\
\hline $\begin{array}{l}\text { F. vísceras suínos } 1 \\
\text { Swine viscera meal } 1\end{array}$ & 93,92 & 45,34 & 15,64 & 4.127 & 1,63 & 26,65 & 11,30 & 6,10 & 0,955 \\
\hline $\begin{array}{l}\text { F. vísceras suínos } 2 \\
\text { Swine viscera meal } 2\end{array}$ & 91,44 & 46,65 & 15,52 & 4.328 & 1,79 & 23,81 & 5,86 & 3,40 & 0,677 \\
\hline $\begin{array}{l}\text { Média } \\
\text { Mean }\end{array}$ & 92,43 & 53,49 & 13,55 & 4.600 & 1,44 & 18,77 & 4,69 & 3,27 & 0,721 \\
\hline $\begin{array}{l}\text { F. penas } 1 \\
\text { Feathers meal } 1\end{array}$ & 90,40 & 76,56 & 4,70 & 5.208 & 0,40 & 3,45 & 0,69 & 2,83 & 0,570 \\
\hline $\begin{array}{l}\text { F. penas } 2 \\
\text { Feathers meal } 2\end{array}$ & 90,04 & 77,00 & 5,45 & 5.216 & 0,51 & 1,40 & 0,28 & 1,38 & 0,666 \\
\hline $\begin{array}{l}\text { F. penas } 3 \\
\text { Feathers meal } 3\end{array}$ & 88,90 & 78,71 & 1,32 & 5.241 & 0,47 & 1,58 & 0,24 & 0,93 & 0,934 \\
\hline $\begin{array}{l}\text { F. penas } 4 \\
\text { Feathers meal } 4\end{array}$ & 89,47 & 81,87 & 2,36 & 5.173 & 0,28 & 1,77 & 0,02 & 1,31 & 0,352 \\
\hline $\begin{array}{l}\text { F. penas } 5 \\
\text { Feathers meal } 5\end{array}$ & 90,87 & 72,29 & 2,62 & 5.141 & 0,24 & 1,55 & 0,23 & 1,25 & 0,663 \\
\hline $\begin{array}{l}\text { F. Penas } 6 \\
\text { Feathers meal } 6\end{array}$ & 89,74 & 73,56 & 10,07 & 5.388 & 0,67 & 2,97 & 0,42 & 1,10 & 1,064 \\
\hline $\begin{array}{l}\text { Média } \\
\text { Mean }\end{array}$ & 89,90 & 76,66 & 4,42 & 5.228 & 0,43 & 2,12 & 0,31 & 1,47 & 0,708 \\
\hline
\end{tabular}

Valores expressos com base na matéria-natural (Values as fed basis).

* Diâmetro geométrico médio (Mean geometric diameter).

mista 2 estão dentro desse padrão. Todas as farinhas de vísceras estão dentro do aceitável, quanto ao nível de EE (mínimo 10\%). Em relação ao teor de matéria mineral (máximo 13\%), apenas as farinhas de vísceras aves 1 e mista 2 estão corretas e todas as farinhas de vísceras ultrapassam a quantidade máxima de fósforo permitida (máximo 1,5\%). Para as farinhas de penas, o teor mínimo de PB é de $80 \%$, do EE, de $2 \%$ e o máximo de $\mathrm{MM}$, de $3 \%$; as farinhas que não estão dentro dos limites aceitáveis são as farinha de penas 1 para MM e farinha de penas 3 para o EE, sendo que apenas a farinha de penas 4 possui mais que $80 \%$ de $\mathrm{PB}$.

As variações encontradas na composição quími- ca e energética dos alimentos já eram esperadas, pois, devido às diferentes matérias-primas utilizadas para a constituição das farinhas, não há uma padronização desses produtos, em virtude de alguns fatores operacionais. Ocorre ainda a interferência do tipo de processamento que cada farinha recebeu, influenciando diretamente a composição química e, conseqüentemente, a qualidade desses alimentos. Este fato enfatiza a importância de determinar a composição dos alimentos, antes da formulação das rações, pois utilizar composições dos alimentos preestabelecidas pode resultar em valores bem diferentes e as necessidades das aves podem não estar sendo atendidas, prejudicando, assim, o seu desempenho. 
Valores de energia metabolizável aparente corrigida e verdadeira corrigida

Os valores de energia metabolizável das farinhas de vísceras e penas foram corrigidos pela retenção de nitrogênio, determinado, portanto, os valores de energia metabolizável aparente corrigida (EMAn), que estão demonstrados nas Tabelas 3 e 4.

A maioria dos valores de EMAn das farinhas de vísceras foi menor, em comparação aos de EMA dos alimentos estudados, independentemente do método utilizado para sua determinação. Essa diminuição ocorreu devido ao balanço nitrogênio positivo das aves.

Não ocorreram diferenças significativas nos valores de EMAn das farinhas de vísceras aves 1 e 5 e das vísceras mista 1 e 2, como também para as farinhas de penas 3,4 e 5 , entre os métodos estudados. Observouse, também, que os valores médios de EMAn das farinhas de vísceras e penas tiveram o mesmo comportamento, mantendo maior valor energético médios para as farinhas, quando determinados pelo método tradicional com galos. Segundo Penz JR. et al. (1999), os valores de EMA, quando são corrigidos pelo balanço de nitrogênio no método tradicional, independente da ave utilizada para o estudo, os valores energéticos dos alimentos tendem a ser similares.

Os valores de EMAn da farinha de penas, determinados pelo método de Sibbald com galos cecectomizados ou intactos, foram idênticos ao valor de $2.952 \mathrm{kcal} / \mathrm{kg}$. Han e Parsons et al.(1991) também verificaram alta correlação nos valores energéticos das farinhas de penas determinados com galos cecectomizados e intactos.

Constatou-se elevação de 393 e 677 kcal $/ \mathrm{kg}$ para o método tradicional com pintos e galos, respectivamente, comparado ao valor com o método de Sibbald. Segundo Sibbald e Wolynetz (1985), há possibilidade de o fator de correção para o balanço de nitrogênio não ser constante.

Os valores de EMAn são encontrados com maior

Tabela 3 - Valores de energia metabolizável aparente corrigida (EMAn) das farinhas de vísceras, expressos na matéria seca ${ }^{1}$

Table 3 - Apparent metabolizable energy correted (AMEn) values of the viscera meal in dry matter ${ }^{1}$

\begin{tabular}{|c|c|c|c|c|}
\hline \multirow[t]{3}{*}{$\begin{array}{l}\text { Farinha de vísceras } \\
\text { Viscera meal }\end{array}$} & \multicolumn{4}{|c|}{$\begin{array}{c}\text { EMAn }-\mathrm{kcal} / \mathrm{kg} \\
A M E n\end{array}$} \\
\hline & \multicolumn{2}{|c|}{$\begin{array}{l}\text { Método tradicional } \\
\text { Traditional method }\end{array}$} & \multicolumn{2}{|c|}{$\begin{array}{l}\text { Método Sibbald } \\
\text { Sibbald method }\end{array}$} \\
\hline & $\begin{array}{l}\text { Pintos } \\
\text { Chicks }\end{array}$ & $\begin{array}{l}\text { Galos } \\
\text { Cocks }\end{array}$ & $\begin{array}{l}\text { Galos* } \\
\text { Cocks* }\end{array}$ & $\begin{array}{l}\text { Galos } \\
\text { Cocks }\end{array}$ \\
\hline $\begin{array}{l}\text { F. de vísceras aves } 1 \\
\text { Poultry viscera meal } 1\end{array}$ & $3.966^{\mathrm{a}}$ & $4.015^{\mathrm{a}}$ & $3.725^{\mathrm{a}}$ & $3.766^{\mathrm{a}}$ \\
\hline $\begin{array}{l}\text { F. de vísceras aves } 2 \\
\text { Poultry viscera meal } 2\end{array}$ & $4.170^{\mathrm{a}}$ & $3.939^{\mathrm{ab}}$ & $3.591^{\mathrm{ab}}$ & $3.359 \mathrm{~b}$ \\
\hline $\begin{array}{l}\text { F. de vísceras aves } 3 \\
\text { Poultry viscera meal } 3\end{array}$ & $3.056^{\mathrm{a}}$ & $2.828^{\mathrm{a}}$ & $2.092 \mathrm{~b}$ & $2.125 \mathrm{~b}$ \\
\hline $\begin{array}{l}\text { F. de vísceras aves } 4 \\
\text { Poultry viscera meal } 4\end{array}$ & $3.470^{\mathrm{a}}$ & $3.342^{\mathrm{ab}}$ & $2.862^{\mathrm{ab}}$ & $2.709^{\mathrm{b}}$ \\
\hline $\begin{array}{l}\text { F. de vísceras aves } 5 \\
\text { Poultry viscera meal } 5\end{array}$ & $3.825^{\mathrm{a}}$ & $4.011^{\mathrm{a}}$ & $3.585^{\mathrm{a}}$ & $3.676^{\mathrm{a}}$ \\
\hline $\begin{array}{l}\text { F. de vísceras mista } 1 \\
\text { Mix viscera meal } 1\end{array}$ & $3.383^{\mathrm{a}}$ & $3.852^{\mathrm{a}}$ & $3.452^{\mathrm{a}}$ & $3.091^{\mathrm{a}}$ \\
\hline $\begin{array}{l}\text { F. de vísceras mista } 2 \\
\text { Mix viscera meal } 2\end{array}$ & $3.433^{\mathrm{a}}$ & $3.529^{\mathrm{a}}$ & $3.341^{\mathrm{a}}$ & $3.439^{\mathrm{a}}$ \\
\hline $\begin{array}{l}\text { F. de vísceras suínos } 1 \\
\text { Swine viscera meal } 1\end{array}$ & $2.693^{b}$ & $3.424^{\mathrm{a}}$ & $2.821^{b}$ & $2.540^{\mathrm{b}}$ \\
\hline $\begin{array}{l}\text { F. de vísceras suínos } 2 \\
\text { Swine viscera meal } 2\end{array}$ & $2.619^{b}$ & $3.647^{\mathrm{a}}$ & $2.892^{b}$ & $2.761^{b}$ \\
\hline $\begin{array}{l}\text { Média } \\
\text { Mean }\end{array}$ & 3.402 & 3.621 & 3.151 & 3.051 \\
\hline $\mathrm{CV}(\%)$ & 10,59 & 4,83 & 9,82 & 15,81 \\
\hline
\end{tabular}

${ }^{1}$ Médias seguidas por letras distintas na linha são diferentes pelo teste de Newman Keuls $(P<0,05)($ Meansby different letters in the line are differents by Newman Keuls test $[P<.05]]$.

* Galos cecectomizados (Cecectomized cocks).

\section{R. Bras.Zootec., v.31, n.3, p.1409-1417, 2002 (suplemento)}


Tabela 4 - Valores de energia metabolizável aparente corrigida (EMAn) das farinhas de penas, expressos na matéria seca ${ }^{1}$

Table 4 - Apparent metabolizable energy correted (AMEn) values of the feathers meal in dry matter ${ }^{1}$

Farinha de vísceras

Viscera meal

EMAn - kcal/kg

\begin{tabular}{|c|c|c|c|c|}
\hline & \\
\hline & \multicolumn{2}{|c|}{$\begin{array}{l}\text { Método tradicional } \\
\text { Traditional method }\end{array}$} & \multicolumn{2}{|c|}{$\begin{array}{l}\text { Método Sibbald } \\
\text { Sibbald method }\end{array}$} \\
\hline & Pintos & Galos & Galos* & Galos \\
\hline & Chicks & Cocks & Cocks* & Cocks \\
\hline F. de penas 1 & $3.077^{b}$ & $3.783^{\mathrm{a}}$ & $2.743^{b}$ & $2.916^{b}$ \\
\hline Feathers meal 1 & & & & \\
\hline F. de penas 2 & $3.264^{\mathrm{ab}}$ & $3.580^{\mathrm{a}}$ & $2.881^{b c}$ & $2.512^{\mathrm{c}}$ \\
\hline Feathers meal 2 & & & & \\
\hline F. de penas 3 & $3.490^{\mathrm{a}}$ & $3.552^{\mathrm{a}}$ & $3.432^{\mathrm{a}}$ & $3.184^{\mathrm{a}}$ \\
\hline Feathers meal 3 & & & & \\
\hline F. de penas 4 & $3.291^{\mathrm{a}}$ & $3.321^{\mathrm{a}}$ & $2.741^{\mathrm{a}}$ & $2.913^{\mathrm{a}}$ \\
\hline Feathers meal 4 & & & & \\
\hline F. de penas 5 & $3.371^{\mathrm{a}}$ & $3.438^{\mathrm{a}}$ & $2.958^{\mathrm{a}}$ & $2.967^{\mathrm{a}}$ \\
\hline Feathers meal 5 & & & & \\
\hline F. de penas 6 & $3.580^{\mathrm{ab}}$ & $4.099^{\mathrm{a}}$ & $2.958^{\mathrm{c}}$ & $3.218^{\mathrm{c}}$ \\
\hline Feathers meal 6 & & & & \\
\hline Média & 3.345 & 3.629 & 2.952 & 2.952 \\
\hline Mean & & & & \\
\hline CV $(\%)$ & 12,97 & 4,52 & 13,26 & 11,14 \\
\hline
\end{tabular}

${ }^{1}$ Médias seguidas por letras distintas na linha são diferentes pelo teste de Newman Keuls $(P<0,05)($ Meansby different letters in the line are

different by Newman Keuls test $[P<.05])$.

* Galos cecectomizados (Cecectomized cocks).

Tabela 5 - Valores de energia metabolizável verdadeira corrigida (EMVn) das farinhas de vísceras, expressos na matéria seca $^{1}$

Table 5 - True metabolizable energy correted (TMEn) values of the viscera meal in dry matter ${ }^{1}$

Farinha de vísceras

Viscera meal
EMVn - kcal/kg TMEn

\begin{tabular}{|c|c|c|c|c|}
\hline & \multicolumn{2}{|c|}{$\begin{array}{c}\text { Método tradicional } \\
\text { Traditional method }\end{array}$} & \multicolumn{2}{|c|}{$\begin{array}{l}\text { Método Sibbald } \\
\text { Sibbald method }\end{array}$} \\
\hline & $\begin{array}{l}\text { Pintos } \\
\text { Chicks }\end{array}$ & $\begin{array}{l}\text { Galos } \\
\text { Cocks }\end{array}$ & $\begin{array}{l}\text { Galos* } \\
\text { Cocks* }\end{array}$ & $\begin{array}{l}\text { Galos } \\
\text { Cocks }\end{array}$ \\
\hline F. de vísceras aves 1 & $3.754^{\mathrm{a}}$ & $3.978^{\mathrm{a}}$ & $3.333^{b}$ & $3.495^{\mathrm{b}}$ \\
\hline $\begin{array}{l}\text { Poultry viscera meal } 1 \\
\text { F. de vísceras aves } 2\end{array}$ & $3.956^{\mathrm{a}}$ & $3.914^{\mathrm{a}}$ & $3.108^{b}$ & $3.079^{\mathrm{b}}$ \\
\hline $\begin{array}{l}\text { F. de vísceras aves } 3 \\
\text { Poultrv viscera meal } 3\end{array}$ & $2.468^{\mathrm{b}}$ & $2.893^{\mathrm{a}}$ & $2.086^{\mathrm{c}}$ & $2.551^{\mathrm{b}}$ \\
\hline $\begin{array}{l}\text { F. de vísceras aves } 4 \\
\text { Poultry viscera meal } 4\end{array}$ & $3.191^{\mathrm{a}}$ & $3.338^{\mathrm{a}}$ & $2.655^{\mathrm{b}}$ & $2.555^{\mathrm{b}}$ \\
\hline $\begin{array}{l}\text { F. de vísceras aves } 5 \\
\text { Poultry viscera meal } 5\end{array}$ & $3.983^{\mathrm{a}}$ & $3.990^{\mathrm{a}}$ & $3.111^{\mathrm{c}}$ & $3.476^{\mathrm{b}}$ \\
\hline $\begin{array}{l}\text { F. de vísceras mista } 1 \\
\text { Mix viscera meal } 1\end{array}$ & $3.485^{\mathrm{b}}$ & $3.905^{\mathrm{a}}$ & $2.997^{\mathrm{c}}$ & $2.753^{\mathrm{d}}$ \\
\hline $\begin{array}{l}\text { F. de vísceras mista } 2 \\
\text { Mix viscera meal } 2\end{array}$ & $2.953^{\mathrm{b}}$ & $3.500^{\mathrm{a}}$ & $2.859^{\mathrm{b}}$ & $3.310^{\mathrm{a}}$ \\
\hline $\begin{array}{l}\text { F. de vísceras suínos } 1 \\
\text { Swine viscera meal } 1\end{array}$ & $2.141^{\mathrm{d}}$ & $3.274^{\mathrm{a}}$ & $2.752^{b}$ & $2.385^{\mathrm{c}}$ \\
\hline $\begin{array}{l}\text { F. de vísceras suínos } 2 \\
\text { Swine viscera meal } 2\end{array}$ & $2.572^{\mathrm{c}}$ & $3.449^{\mathrm{a}}$ & $2.892^{\mathrm{b}}$ & $2.555^{\mathrm{c}}$ \\
\hline $\begin{array}{l}\text { Média } \\
\text { Mean }\end{array}$ & 3.167 & 3.583 & 2.866 & 2.906 \\
\hline CV $(\%)$ & 5,88 & 3,91 & 5,50 & 5,75 \\
\hline
\end{tabular}

\section{R. Bras. Zootec., v.31, n.3, p.1409-1417, 2002 (suplemento)}


Tabela 6 - Valores de energia metabolizável verdadeira corrigida (EMVn) das farinhas de penas, expressos na matéria seca $^{1}$

Table 6 - True metabolizable energy correted (TMEn) values of the feathers meal in dry matter ${ }^{1}$

\begin{tabular}{|c|c|c|c|c|}
\hline \multirow[t]{3}{*}{$\begin{array}{l}\text { Farinha de vísceras } \\
\text { Viscera meal }\end{array}$} & \multicolumn{4}{|c|}{$\begin{array}{c}\mathrm{EMVn}-\mathrm{kcal} / \mathrm{kg} \\
T M E n\end{array}$} \\
\hline & \multicolumn{2}{|c|}{$\begin{array}{l}\text { Método tradicional } \\
\text { Traditional method }\end{array}$} & \multicolumn{2}{|c|}{$\begin{array}{l}\text { Método Sibbald } \\
\text { Sibbald method }\end{array}$} \\
\hline & $\begin{array}{l}\text { Pintos } \\
\text { Chicks }\end{array}$ & $\begin{array}{l}\text { Galos } \\
\text { Cocks }\end{array}$ & $\begin{array}{l}\text { Galos* } \\
\text { Cocks* }\end{array}$ & $\begin{array}{l}\text { Galos } \\
\text { Cocks } \\
\end{array}$ \\
\hline $\begin{array}{l}\text { F. de penas } 1 \\
\text { Feathers meal } 1\end{array}$ & $3.201^{b}$ & $3.976^{\mathrm{a}}$ & $2.717^{\mathrm{c}}$ & $2.591^{\mathrm{c}}$ \\
\hline $\begin{array}{l}\text { F. de penas } 2 \\
\text { Feathers meal } 2\end{array}$ & $2.894^{b}$ & $3.835^{\mathrm{a}}$ & $2.702^{b}$ & $2.662^{b}$ \\
\hline $\begin{array}{l}\text { F. de penas } 3 \\
\text { Feathers meal } 3\end{array}$ & $2.938^{b}$ & $3.509^{\mathrm{a}}$ & $2.867^{\mathrm{b}}$ & $2.904^{\mathrm{b}}$ \\
\hline $\begin{array}{l}\text { F. de penas } 4 \\
\text { Feathers meal } 4\end{array}$ & $3.061^{\mathrm{a}}$ & $3.300^{\mathrm{a}}$ & $2.405^{\mathrm{b}}$ & $2.443^{b}$ \\
\hline $\begin{array}{l}\text { F. de penas } 5 \\
\text { Feathers meal } 5\end{array}$ & $3.147^{b}$ & $3.417^{\mathrm{a}}$ & $2.628^{c}$ & $2.413^{\mathrm{c}}$ \\
\hline $\begin{array}{l}\text { F. de penas } 6 \\
\text { Feathers meal } 6\end{array}$ & $3.187^{b}$ & $3.989^{\mathrm{a}}$ & $3.346^{\mathrm{b}}$ & $3.202^{\mathrm{b}}$ \\
\hline $\begin{array}{l}\text { Média } \\
\text { Mean }\end{array}$ & 3.071 & 3.671 & 2.777 & 2.703 \\
\hline CV $(\%)$ & 7,71 & 5,66 & 6,80 & 5,09 \\
\hline
\end{tabular}

${ }^{1}$ Médias seguidas por letras distintas na horizontal diferem pelo teste Newman Keuls $(P<0,05)$ (Means by different letters in the lineare differents by Newman Keuls test $[P<.05])$.

* Galoscecectomizados (Cecectomized cocks).

freqüência nas tabelas de composição dos alimentos, pois são utilizados diretamente na formulação de rações; observando a média dos valores de EMAn das farinhas de vísceras e penas, verifica-se que são maiores que os valores relatados por Rostagno et al. (1983), pela EMBRAPA (1990) e pelo NRC (1994).

Nas Tabelas 5 e 6 são apresentados os valores de energia metabolizável verdadeira corrigida pela retenção de nitrogênio (EMVn), para os alimentos estudados.

Foram verificadas diferenças nos valores de EMVn das farinhas de vísceras e penas, determinados pelos diferentes métodos, sendo que os maiores valores energéticos (EMVn) foram observados quando se utilizou o método tradicional com galos.

Observou-se que, somente em quatro farinhas de vísceras e uma farinha de penas, os valores de EMVn determinados pelo método tradicional não diferiram significativamente, usando categoria de aves diferentes. Entretanto, a variação dos valores energéticos médios das farinhas, entre a utilização de pintos ou galos, para este método foi de 416 e $600 \mathrm{kcal}$ para a farinha de vísceras e penas, respectivamente.

Foram feitas correlações entre os métodos estudados; os resultados são apresentados na Tabela 7.

Entre as metodologias, as correlações foram baixas e, ainda, diferentes, dependendo da energia metabolizável estimada. Infere-se portanto que, parte das diferenças encontradas nos valores energéticos dos alimentos deve-se às diferentes metodologias utilizadas.

\section{Conclusões}

Os valores médios de energia metabolizável aparente corrigida (EMAn) para a farinha de vísceras foram $3.402,3.621,3.151 \mathrm{e} 3.051 \mathrm{kcal} / \mathrm{kg}$ e para as farinhas de penas, 3.345, 3.629, 2.952 e $2.952 \mathrm{kcal} / \mathrm{kg}$, respectivamente, para o método tradicional com pintos, método tradicional com galos, método de Sibbald com galos cecectomizados e com galos intactos.

Observou-se grande variação na composição química e energética das farinhas de vísceras e penas, o que interferiu diretamente no valor de energia metabolizável desses alimentos.

Os valores de energia metabolizável dos alimentos foram diferentes, quando determinados pelo método tradicional com pintos de corte ou com galos.

O método de Sibbald, usando galos intactos ou cecectomizados, proporcionou valores energéticos das farinhas de vísceras e penas semelhantes entre si, porém menores, quando determinados como método tradicional. 
Tabela 7 - Coeficientes de correlação entre os métodos ${ }^{1}$

Table 7 - Correlation coefficient in the methods ${ }^{1}$

\begin{tabular}{|c|c|c|c|c|}
\hline \multirow[t]{2}{*}{$\begin{array}{l}\text { Variáveis } \\
\text { Variables }\end{array}$} & \multicolumn{2}{|c|}{$\begin{array}{l}\text { Método tradicional } \\
\text { Traditional method }\end{array}$} & \multicolumn{2}{|c|}{$\begin{array}{l}\text { Método Sibbald } \\
\text { Sibbald method }\end{array}$} \\
\hline & $\begin{array}{l}\text { Pintos } \\
\text { Chicks }\end{array}$ & $\begin{array}{l}\text { Galos } \\
\text { Cocks }\end{array}$ & $\begin{array}{l}\text { Galos cecectomizados } \\
\text { Cecectomized cocks }\end{array}$ & $\begin{array}{c}\text { Galos intactos } \\
\text { Cocks }\end{array}$ \\
\hline $\begin{array}{l}\text { EMAn } \\
A M E n\end{array}$ & & & & \\
\hline $\begin{array}{l}\text { Tradicional pintos } \\
\text { Chicks traditional }\end{array}$ & & $0,57^{*}$ & $0,35^{*}$ & $0,45^{*}$ \\
\hline $\begin{array}{l}\text { Tradicional galos } \\
\text { Cocks traditional }\end{array}$ & & & $0,57^{*}$ & $0,45^{*}$ \\
\hline $\begin{array}{l}\text { Sibbald galos cecectomizados } \\
\text { Cocks Sibbald traditional } \\
\text { EMVn-TMEn }\end{array}$ & & & $0,57^{*}$ & \\
\hline $\begin{array}{l}\text { Tradicional pintos } \\
\text { Chicks traditional }\end{array}$ & & $0,65^{*}$ & $0,50 *$ & $0,65^{*}$ \\
\hline $\begin{array}{l}\text { Tradicional galos } \\
\text { Cocks traditional }\end{array}$ & & & $0,64^{*}$ & $0,65^{*}$ \\
\hline $\begin{array}{l}\text { Sibbald galos cecectomizados } \\
\text { Cocks Sibbald traditional }\end{array}$ & & & $0,65^{*}$ & \\
\hline
\end{tabular}

${ }^{1}$ Teste de Pearson * $(\mathrm{P}<0,001)$.

\section{Literatura Citada}

ALBINO, L.F.T.; SILVA, M.A. Valores nutritivos de alimentos para aves e suínos determinados no Brasil. In: SIMPÓSIO INTERNACIONAL SOBRE EXIGÊNCIAS NUTRICIONAIS DE AVES E SUÍNOS, 1996, Viçosa, MG. Anais... Viçosa, MG: Universidade Federal de Viçosa, 1996. p.303-318.

ALBINO, L.F.T.; ROSTAGNO, H.S.; TAFURI, M.L. et al. Determinação dos valores de energia metabolizável aparente e verdadeira de alguns alimentos para aves, usando diferentes métodos. Revista da Sociedade Brasileira de Zootecnia, v.21, n.6, p.1047-1057, 1992.

ANFAR Matérias-primas para alimentação animal - PADRÃO, Sindirações/ ANFAR, 1998.

AZEVEDO, D.M.S. Fatores que influenciam os valores de energia metabolizável da farinha de carne e ossos para aves. Viçosa, MG: Universidade Federal de Viçosa, 1997. 58p. Dissertação (Mestrado em Zootecnia) - Universidade Federal de Viçosa, 1997.

EMPRESA BRASILEIRA DE PESQUISA AGROPECUÁRIA - EMBRAPA. Centro Nacional de Pesquisa de Suínos e Aves (Concórdia, SC). Tabela de composição química e valores energéticos de alimentos para suínos e aves. 3.ed. Concórdia, 1991. 97p.

HAN, Y.; PARSONS, C.M. Protein and amino acid quality of feather meals. Poultry Science, v.70, p.812-822, 1991.

MATTERSON, L.D.; POTTER, L.M.; STUTZ, N.W. et al. The metabolizable energy of feeds ingredient for chickens. Storrs: University of Connecticut - Agricultural Experiment Station, 1965. 11p. (Research Report, 7).

NATIONAL RESEARCH COUNCIL - NRC. Nutrient requirements of poultry. 9.ed. Washington, D.C: National Academy Press, 1994. 155p.

NATIONAL RESEARCH COUNCIL - NRC. Nutrient requirements of swine. 10.ed. Washington, D.C.: National Academy Press, 1998. 189p.

R. Bras.Zootec., v.31, n.3, p.1409-1417, 2002 (suplemento)
PUPA, J.M.R.; LEÃO, M.I.; CARVALHO, A.U. et al. Cecectomia em galos sob anestesia local e incisão abdominal. Arquivo Brasileiro de Medicina Veterinária e Zootecnia, v.50, n.5, p.531-535, 1998.

RUTZ, F.; PENZ Jr., A.M.; ROLL, V.F.B. Tendências em nutrição de aves. In: SIMPÓSIO INTERNACIONAL ACAV - EMBRAPA SOBRE NUTRIÇÃO DE AVES, 1., 1999, Concórdia. Anais ... Concórdia, 1999. p.66-98.

SIBBALD, I.R. A biossay for true metabolizable energy in feedingstuffs. Poultry Science, v.55, p.303-308, 1976.

SIBBALD, I.R.; WOLYNETZ, M.S. Relationships between estimates of biovailable energy made with adult cockerels and chicks: effects of feed intake na nitrogen retention. Poultry Science, v.64, p.127-138, 1985.

SILVA, D.J. Análise de alimentos: métodos químicos e biológicos. 2.ed. Viçosa, MG: Universidade Federal de Viçosa, 1990. 165 p.

UNIVERSIDADE FEDERAL DE VIÇOSA - UFV. SAEG. Central de Processamento de Dados - UFV/CPD. SAEG - Sistema de Análise Estatística e Genética, Viçosa, MG: Universidade Federal de Viçosa, 1992. 59p.

ZANOTTO, D.L.; BELLAVER, C. Método de determinação da granulometria de ingredientes para uso em rações de suínos e aves. Concórdia: EMBRAPA - CNPSA, 1996. 5p. (Comunicado Técnico)

Recebido em: 31/08/01

Aceito em: 28/03/02 